\title{
Modeling Population Dynamics in the City: from a Regional to a Multi-Agent Approach
}

\author{
ITZHAK BENENSON* \\ Department of Geography, Tel-Aviv University, Ramat-Aviv, Israel, 69978
}

(Received 16 November 1998)

\begin{abstract}
The paper reviews different approaches to urban population from the point of view of the theory of complex systems. Regional models deal with large numbers of urban regions involved in exchanging population and resources among themselves. In contrast, ecological models deal with several qualitatively different types of relationships between a small number of components, aimed at understanding the most general laws of urban dynamic. Two relatively new approaches, namely Cellular Automata and multi-agent ones describe the macro-processes resulting from uniform collective processes at the micro-level of land parcels and migrating city individuals. Recent results of the multi-agent simulations regarding abstract and real-world systems are presented in more details.
\end{abstract}

Keywords: Urban modeling, Regional modeling, Ecological modeling, Cellular Automata, Multi-agent simulations, GIS-based modeling

1 URBAN MODELING: FROM INTEGRAL DESCRIPTION TO THE DESCRIPTION OF CITY COMPONENTS

Approaches to urban population dynamics modeling evolved in parallel to the evolution of the theory of complex systems. Historically, the regional approach dated from the sixties and rooted in cybernetics of the fifties, was the first developed. Regional modeling is based on the presentation of a geographical system (city, metropolitan, administrative region) by means of "zones", which exchange population, goods, capital, etc. among themselves. Most regional models are economically oriented, with each zone characterized by a vector of socioeconomic indicators. Components of this vector are numbers/proportions of population groups in a zone according to their age, culture, education or employment, as well as the numbers/proportions of jobs in different industries, dwellings of different kinds, services of different types, etc.

The initial goal of regional approach was the simulation of real systems. This operational aspect turned out to be problematic after its initial applications. On the one hand, even a minimal division of a city's territory into zones and its population into socio-economic groups requires dozens of equations and the estimation of hundreds

*Tel.: +972-3-6409178. Fax: +972-3-6406243. E-mail: bennya@ccsg.tau.ac.il. 
of parameters. On the other, although the behavior of solutions of the regional models is insensitive to some of parameters and sensitive to others, the sets of the most influential parameters cannot be identified until construction of the model has been completed. The inconsistencies were resolved during the 1970s and 1980s with the development of the general theory of complex systems. Seminal works by Prigogine (Prigogine, 1967; Nicolis and Prigogine, 1977) on "dissipative systems" and by Haken $(1978,1993)$ on "synergetics" made clear that open complex systems (including urban ones) reveal common laws of behavior. Stated briefly, according to Haken, for example, the evolution of external "control" parameters entails the bifurcation of city dynamics. In the vicinity of the point of bifurcation, the trajectory of the system belongs to a low-dimensional subspace, which is defined by slowly varying characteristics of the system and can be described by few "order parameters" that "enslave" the rest of system's rapidly changing "fast" characteristics. The new factors, which represent slow order and fast characteristics of the system are functions of the original variables, but do not coincide with them.

The results of complex system theory, which became the "paradigm" for regional analysis, essentially influenced the future of urban modeling. The paradigm basic idea is as follows: A qualitative understanding of urban dynamics does not demand a detailed description of all the interrelations established among the components. We are required to understand only the most important and, perhaps, latent orders of urban dynamics, to classify their possible interactions, and to interpret qualitatively different outcomes. As for quantitative description of urban dynamics, the problem remains open if the order parameters uncovered by the mathematical analysis differ from those variables we are interested in.

Consequently, we can understand urban dynamics qualitatively by reducing the number of components and socio-economic indicators of the model from hundreds to a few units. In contrast, in order to study those dynamics quantitatively, we have to include the additional information necessary to provide clues about the internal orders of a certain urban system.

The achievements made by the qualitative approach are based on the application of mathematical ecology models to urban systems (Day, 1981; Dendrinos and Mullally, 1982; 1985; Zhang, 1989; Dendrinos and Sonis, 1990). Regarding population dynamics, we can cite studies of competition between two social groups for space (Zhang, 1989), or studies of "predator-prey" relationships between density and economic status of city population (Dendrinos and Mullally, 1982; 1985).

The novel successor to multi-component regional modeling is the Cellular Automata (CA) approach to modeling city infrastructure (Tobler, 1979; Phipps, 1989; 1992; Phipps and Langlois, 1997; White and Engelen, 1993; Batty and Xie, 1994; Durrett and Levin, 1994; Wu, 1996; White et al., 1997; Rapini and Rabino, 1997). Formally, a CA is a regular lattice of cells appearing in alternating states, which changes according to the state of the cell itself and its neighbors. In urban applications, cell states reflect properties of the city's parcels, namely, the type of land usage or economic potential. The definition of cell states as land uses entails essential constraints on CA applications. First, it implies limitations on the cell size - the latter should be sufficiently small to retain internal homogeneity; second, it places lower limits on the duration of the model's iteration - land usage does not change in days or even months. At the same time, for properly chosen characteristic cell size and time step, the estimation of CA parameters can be done straightforwardly, according to the city maps of consecutive years (White and Engelen, 1993).

An important brand of CA models simulates the fractal structure of the city. Fractal and CA approaches differ in the mechanisms they use for generating urban patterns. From the broad spectrum of local interaction mechanisms, fractal models utilize the Diffusion Limited Aggregation scheme, which allows to generate spatial patterns of given fractal dimension. 
CA and fractal approaches are very promising regarding the description of the physical structure of a city. However, for obvious reasons, they do not account for "soft" component, namely, for the structure and distribution of the city's population. Spatial population dynamics in the city is an outcome of the individuals' decisions and residential behavior. The latter are considered explicitly in the framework of the multi-agent (MA) models (Maes, 1995; Openshow, 1995; Portugali and Benenson, 1995; 1997; Conte et al., 1997; Troitzsch et al., 1996). The general aim of MA models is to investigate the consequences of social interactions in the urban context. Individuals are represented in MA models as free agents who exhibit the economic and cultural properties of human beings and who change their location in the city. In the MA framework, spatial and temporal resolutions are constrained from above: first, the residential decision is based on information on separate apartments or houses; second, relatively high numbers of individuals change their residence during any month or even shorter time interval. As a result, MA models study rapidly transpiring urban phenomena, particularly the emergence of residential segregation in the urban space.

To conclude, regional models deal with large numbers of urban regions involved in exchanging population and resources among themselves. In contrast, ecological models, which deal with several qualitatively different types of relationships between a small number of components, aimed at understanding the most general laws of urban dynamic. A new set of models, CA and MA models describe the macro-processes resulting from collective behavior at the micro-level of land parcels and migrating city individuals. More specifically, CA models deal with the relatively slow changes undergone by the urban infrastructure and provide the background for MA simulations of relatively rapid changes in the population's spatial structure.

In this paper different approaches to urban modeling with respect to population dynamics are compared. A hierarchical combination of CA and MA micro-approaches is suggested as a tool for the simultaneous modeling of urban infrastructure and population dynamics.

\section{THE MAINSTREAMS OF URBAN MODELING}

\subsection{Black-box Macro-Modeling}

\subsubsection{Ecological Approach}

Much effort has been invested in studies of urban population dynamics suggesting different types of interactions between population groups and the other urban components. Most of these results can be considered as applications of ecological models to urban situations. Mathematical ecology (see Murray, 1993, among numerous texts) has an almost hundred-year history of development, and dynamic models of simple ecological systems consisting of one or two interacting populations are among the most elaborated examples of this approach. Qualitatively, the behavior of a model's solutions depends on the feedback between population density and growth rate for a one-species system or on the type of inter-species interaction for a two-species system. Several qualitatively different types of feedback relations (linear, exponential, etc.) and interactions (competition, predator-prey, parasite-host, etc.) have been studied and their consequences classified. Many of the subsequent results regarding plant and animal species have direct urban interpretations. For example, Dendrinos and Mullally (1982, 1985) consider urban dynamics as interplay between the city's population size and an individual's economic status:

$$
\begin{aligned}
& \mathrm{d} X /(X \cdot \mathrm{d} t)=\alpha \cdot\left(Y-Y_{\mathrm{m}}\right)-\beta \cdot X \\
& \mathrm{~d} Y /(Y \cdot \mathrm{d} t)=\gamma \cdot\left(X_{\mathrm{m}}-X\right),
\end{aligned}
$$

where $X$ denotes relative population size, $Y$ is deflated per capita income, $X_{\mathrm{m}}$ is the city's carrying capacity in terms of population size, $Y_{\mathrm{m}}$ is prevailing deflated per capita income. 
The solutions of (1) depend on the type of socio-economic interactions, the latter determined by the parameters $\alpha, \beta$ and $\gamma$. The estimates of the parameters for 32 US metropolitan areas (Dendrinos and Mullally, 1982) best fit those interactions between population size and income that correspond formally to the predator-prey type of relationships and provide oscillating convergence to an equilibrium. According to the parameter estimates, the period of converging oscillations for cities in the sample ranges between 20 and 150 years.

The above model does not account directly for the critical process of spatial diffusion. The simplest way to do so is to assume a radial symmetry of population distribution and to add the diffusion term to the equation for non-spatial population dynamics. For a logistic description of population growth, the resulting model looks as follows:

$$
\begin{aligned}
\mathrm{d} N / \mathrm{d} t= & \alpha \cdot(1-N) \cdot N+D \cdot(1 / r \cdot \mathrm{d} N / \mathrm{d} r \\
& \left.+\mathrm{d}^{2} N / \mathrm{d} r^{2}\right),
\end{aligned}
$$

where $r$ is the distance from the center of the area.

O'Neil (1981), who investigated the ability of this simple model to approximate the process of expansion of the black ghetto in Chicago during 19681972, obtained a good agreement of the solution of the above equation with the observed data. The equation that best fits the experimental data is as following:

$$
\begin{aligned}
\mathrm{d} N / \mathrm{d} t= & 0.191 \cdot(1-N) \cdot N+0.128 \\
& \cdot\left(1 / r \cdot \mathrm{d} N / \mathrm{d} r+\mathrm{d}^{2} N / \mathrm{d} r^{2}\right) .
\end{aligned}
$$

The coefficient of determination equals $r^{2}=0.79$, and is significant at $p<0.001$.

Zhang (1989) has been developing a theoretical model of the urban dynamics in which the population consists of two groups competing for space:

$$
\begin{aligned}
\mathrm{d} X / \mathrm{d} t= & \alpha \cdot(a-b \cdot X-c \cdot Y) \cdot X-d_{1} \cdot X \cdot Y \\
& +D_{X} \cdot \mathrm{d}^{2} X / \mathrm{d} r^{2}, \\
\mathrm{~d} Y / \mathrm{d} t= & \beta \cdot(a-b \cdot X-c \cdot Y) \cdot Y-d_{2} \cdot X \cdot Y \\
& +D_{Y} \cdot \mathrm{d}^{2} Y / \mathrm{d} r^{2},
\end{aligned}
$$

where group densities $X(r, t)$ and $Y(r, t)$ depend on distance $r$ to CBD. Possible interactions between the members of the groups are expressed by positive or negative values of $d_{1}$ and $d_{2}$. Zhang (1989) interprets a positive $d_{1}$ and negative $d_{2}$, for instance, as a desire of less-educated population $X$ to live with the more educated population $Y$. Expressions $D_{X} \cdot \mathrm{d}^{2} X / \mathrm{d} r^{2}$ and $D_{Y} \cdot \mathrm{d}^{2} Y / \mathrm{d} r^{2}$ describe the diffusion of the individuals.

When solving for (4) we eventually obtain either a homogeneous city where only $X$ - or $Y$-individuals remain, or a city where both groups persist. Zhang (1989) has proved that the number of qualitatively different outcomes of (4) is less than for the corresponding non-spatial model. Namely, the oscillating solutions do not exist, and we can conclude, therefore, that migration stabilizes urban system dynamics.

To summarize, within the framework of ecological approach urban dynamics is defined by interactions between limited number of social groups. The system's dynamic patterns are qualitatively classified according to the types of interaction. For those specific situations, where low number of variables is sufficient, a correspondence between model results and experimental data can be achieved.

\subsubsection{Regional Models}

Ecological models intentionally simplify urban population structures and urban systems. The description of urban population dynamics that can be attuned to real world situations demands plenty of components and relationships are accounted for, and regional models try to account explicitly for urban complexity. In the regional framework, each zone is characterized usually by two sets of variables, the first one representing the properties of the city's physical environment and the second those of the city population. To illustrate, Peter Allen and his colleagues (Allen and Sanglier, 1979; 1981; Allen, 1982; Allen et al., 1986; Engelen, 1988), by adopting this approach, attempted to simulate the dynamics of the city of Brussels, the economic development of North Holland, the economics of Belgium as 
a whole, etc. We consider here the model of an artificial city, "Brusseville", whose structure reflects that of Brussels (Engelen, 1988).

According to the logic of regional modeling, Brusseville is divided into $N=36$ spatial zones. Each zone $i$ is characterized by a vector $v_{i}$, which consists of "population" and "socio-economic" subvectors. The population sub-vector, in turn, consists of two sets of components, representing the properties of white- and blue-collar residents. Each set is characterized by the number of active residents $x_{i}$, the number of non-active residents $n_{i}$, and the variables representing migration flows. The socioeconomic sub-vector accounts for the quality of the neighborhoods, the housing stock $H_{i}$, and the level of employment of different types (finance, heavy industry, etc.). The crucial element of the model is the definition of the zones' interactions, the number of which for a system divided into $N$ zones is of an order of $N^{2}$. Bearing in mind the potential applications, the authors intentionally keep the number of independent parameters describing these interactions to an order of $N$. To do so, they introduce the potential attractivity $R_{i}$ of zone $i$ and describe residential movements as a two-stage process. At the first stage emigrants leave the zones where they live; at the second they choose a new residence according to the zone's attractivity, irrespective of the parameters of the zone they left. In order to account for the distances between the zones of origin and destination, the attractivity of zone $i$ for the migrant from zone $j$ is given by $R_{i} \cdot \exp \left(-\tau \cdot d_{i j}\right)$, where $d_{i j}$ is the distance between zones $i$ and $j$.

The dynamics of population groups is described in the model by means of the logistic relationships. For instance, the dynamics of the active population of zone $i$ is described as

$$
\mathrm{d} x_{i}^{\mathrm{g}} / \mathrm{d} t=\varepsilon^{\mathrm{g}} \cdot n_{i}^{\mathrm{g}} \cdot\left(J_{i}^{\mathrm{g}}-x_{i}^{\mathrm{g}}\right),
$$

where $\mathrm{g}$ denotes the population group (whiteor blue-collar), and $\varepsilon^{\mathrm{g}}$ is a net rate of employment of non-active residents $n_{i}$ as white- or bluecollar employers, and $J_{i}$ is an overall potential employment.
The dynamics of the spatial patterns generated by the Brusseville model are studied according to scenarios. In one scenario, for instance, the canal that crosses the city is replaced by a line of hills (Engelen, 1988). As a result of this dramatic change of the city's infrastructure, the industry that was concentrated along the canal spreads out along the perimeter of the city, where crowding is less and land is cheaper. Following these changes white-collar residents move from the city's outskirts towards the new hill area, where they have good access to the CBD and are far from the nuisances marred by industry.

Van Wissen and Rima (1988) constructed a comprehensive regional model of Amsterdam population dynamics. They represent Amsterdam and surrounding area by means of 20 zones. In each zone, 11 dwelling types and 24 types of households of four different sizes are distinguished. The intensity of migration and the residential choice of each family is dependent upon the age of the head of household (according to 5-year age categories) and on the number of family members (seven groups). In addition, immigration, emigration and birth and death processes are included. The parameters of the model were estimated based on detailed household and migration data for each zone for the period 1971-1984. The quality and resolution of empirical data were sufficient to provide a very good approximation of population and household dynamics. For thirteen zones, the $R^{2}$ statistics of correspondence between actual data and model results were higher than 0.9 ; for the remaining zones, excluding one, it was not less than 0.5. Based on this correspondence, two scenarios of Amsterdam population and household dynamics for 1985-2000 were compared. The first reflects central government plans to build new dwellings in Amsterdam, while the second reflects local government measures to decrease construction quotas in the expanding suburbs. The short period of prognosis implies rather similar predictions for both scenarios. They diverge at the level of 10 percent or less for most of the parameters, including total population and number of households as well as population and household numbers per zone. 
Batty and Longley (1994) consider a similar, but less detailed model of residential choice in Greater London. In their study the city is divided into 32 zones, each one described by the percentages of dwellings of four types, namely of purpose-built flats, converted flats, row houses and single-family houses. The probabilities of occupying the dwellings of each type are considered as functions of the distance between the CBD and the zone and of the mean age of the dwellings in the zone. As in Brusseville model, the attractivity of the potential dwelling of a certain type does not depend on individual's current occupation.

The overall percentage of correct predictions given by this less detailed London model is lower than in an Amsterdam's one and equals 0.432. Spatially, prediction is much better for zones close to the CBD and for the outermost suburbs than for the intermediate zones.

A number of attempts (Anselin and Madden, 1990; Putman, 1990; Bertuglia et al., 1994; Tadei and Williams, 1994) have been undertaken to combine the main components of the city in the framework of one model. Bertuglia et al. (1994) present the most general formulation of this approach - the Integrated Urban Model (IUM). They declare the following components as sufficient for the description of urban dynamics: the housing market, the job market, the service sector, the land market, and the transportation subsystem. The state of these components is described by the following groups of variables: the numbers of population groups, the housing stock, industry, and employment according to branches. Spatially, the city is divided into $N$ zones, where individuals can live and work. The IUM operates with the flows of population between the zones, while considering the costs of the trips.

The dimensions of the model's description are the main problem of the IUM approach. In order to describe the flow of workers, for instance, the model accounts for the fraction of workplaces in zone $j$ occupied by workers living in zone $i$ at the current iteration, but occupied at the next iteration by workers living in zone $k$. If the number of spatial zones equals $N$, then the dimension of this description has an order of $N^{3}(!)$ and it seems impossible to obtain any reasonable estimates of the parameters. As a result, the IUM is a representational rather than modeling tool.

Thus, ecological models have a simple structure, but deal with selected factors only, while regional models are too complex and almost always lack parameters' estimates. Are there any intermediate approaches? CA and MA models present a positive response. Both are based on accounting for the local spatial structure of the city.

\subsection{Individual-based Micro-Modeling}

The ecological and regional approaches utilize topdown approaches to the complex system studies. Within their frameworks, an urban system is expanded into a predetermined number of components, and this expansion is maintained throughout. Micro-approach, in comparison, is based on a bottom-up representation of the city as the collective of potentially infinite numbers of elementary units whose interactions define dynamics of the urban system at large. From the latter point of view, the urban model must include at least $t w o$ different elementary units, namely land parcels and migrating individuals.

The dynamics of the city as coverage of parcels is studied by means of CA, while individual interactions are considered in the framework of MA models.

\subsubsection{Cellular Automata as the Background for Individual-based Modeling}

The basic features of CA models are as follows:

- A city is represented by the two-dimensional lattice of cells $C_{i j}$;

- Time advances in discrete steps;

- Each cell $C_{i j}$ is found in some state $s$ that belongs to a finite set $S=\left\{s_{1}, s_{2}, \ldots, s_{K}\right\}$;

- The cells change their states according to local transition rules. That is, the state of the cell itself 
and the states of the cell's neighbors at the current time step define the state of the cell at the next time step.

Various versions of CA models include varying in space and time form and size of the neighborhood, deterministic and stochastic transition rules, dependence of transition rules on the location of the cell within the lattice, the current state of the cell, etc.

Tobler (1979) was the first to recognize and state the advantages of CA approach for the describing urban dynamics. Phipps $(1989,1992)$ and Couclelis (1985) implemented a general CA model for the description of urban dynamics. They recognized and studied the phenomenon of the emergence of regular spatial structures of cells from an initially disordered lattice. This basic property of CA was intensively studied during the 1980 s for one-dimensional CA models. Urban interpretations, however, demand two-dimensional CA; their different versions were investigated in a number of papers (Phipps, 1989; 1992; Portugali et al., 1994; Durrett and Levin, 1994; Hegselmann, 1996). The results were quite similar to those obtained in one-dimensional models. Namely, if we suppose that the cell changes its state towards the modal state of the neighboring cells, then $\mathrm{CA}$ as a whole evolves toward the persistent "segregated" state. In this state the CA consists of segregated domains of cells, those within the domain having similar states.

Recently, a number of operational CA models at the city and regional level were developed. Some of these models well fit real-world cities (Batty and Xie, 1994; Itami, 1994; Benati, 1997; Wu, 1996; White et al., 1997). As an example let us consider the CA simulation of the city of Cincinnati (White et al., 1997). The city is represented in the model as an $80 \times 80$ lattice of cells. Cell states represent land uses and are of two classes: active states that can change, namely housing, commerce and industry; and fixed states, used to represent infrastructure, i.e. rivers, railways, and roads. Although cells in fixed states do not change, they can affect the transitions of other cells from one state to another. Cell neighborhood consists of the 112 cells lying within the circle of radius six cells. Such unusually large neighborhood permits a more realistic modeling of local interaction effects among land uses. In order to make the model operational, the transition rules are stochastic depending upon the current state of the cell and on the cell location within the city lattice.

The simulations conducted by White et al. (1997) were calibrated to fit Cincinnati land-use data, beginning from 1960. In general, the model reproduces morphology of Cincinnati, both visually and in terms of the statistical measures of spatial similarity. Based on this correspondence, a series of simulation experiments was held in order to clarify the role of transportation network changes on Cincinnati dynamics.

The generalized CA approach was implemented in several other studies (Batty and Xie, 1994; Itami, 1994; Wu, 1996; Benati, 1997; Sanders et al., 1997). In all of them, the outcomes significantly agree with the dynamics of real cities.

In addition to its use in direct $C A$ simulations, the representation of a city as a lattice of cells provides a basis for the fractal approach to the description of urban morphology. The main assumption of the fractal approach is that of self-similarity of the pattern in case; in other words, zooming of the city street network, housing, etc. pattern provides geometrical structures similar to that at the previous level of resolution. From the geographical point of view, the fractal approach generalizes the classic description of settlement hierarchies conceptualized by Von Thunen and Christaller (Batty and Longley, 1994).

Self-similar geometrical patterns can be characterized by a "fractal dimension", which is a rational number that nonetheless differs from the standard topological dimension of one, two, or three. A fractal dimension is used for the analysis and comparison of different urban structures, e.g. regional boundaries, traffic networks, or residential and industrial areas (Batty and Longley, 1994; Frankhauser, 1994; Schweitzer and Steinbrink, 1997). The estimates of the fractal dimensions for urban housing patterns fluctuate between 1.3 and 
1.9 , with a modal value about 1.7 . The fractal dimensions of urban networks (the topological dimension of which equals one) fluctuates between 1.1 and 1.9, with a modal value close to 1.4 .

If a fractal dimension characterizes urban patterns, then the model that generates the geometrical pattern of a given fractal dimension can serve as a tool for simulating a city's geometry. The most popular mechanism for generating fractal structures is Diffusion-Limited Aggregation (DLA) and its generalizations. This model is an extension of a random walk model on a rectangular lattice.

Fractal models produce quite likelihood urban patterns at low spatial and temporal resolution. Frankhauser (1994) and Schweitzer and Steinbrink (1997) have imitated in this way the rank distribution of settlements of Berlin metropolis in 1945 based on the data on 1910. Batty and Longley (1994) have made a thorough investigation of the fractalgenerating models, both at the theoretical level and in relation to the growth of real-world cities. They have demonstrated, for instance, very good correspondence between the fractal dimension of actual Cardiff land-use pattern and the model simulation 1.772 versus 1.75 .

To conclude, the encouraging results of the simulations of several cities by means of CA and fractal models make them serious nominees for including among the standard tools used for modeling urban infrastructure at low and intermediate spatial and temporal resolution. Regarding the human component, CA and fractal models do not consider it at all. Straightforward scheme for simulating social processes in the city is provided, instead, by the multi-agent approach, presented below in detail.

\subsubsection{Multi-agent Simulations of Urban Population Dynamics}

CA models ignore two basic properties of a city as a populated system. First, the city's physical structure develops according to the demands of its population. Second, the city's inhabitants, unlike elementary units of non-living systems, are them- selves complex systems, whose properties can change during the course of the lifetime. In order to account for these basic properties, MA approach operates with a two-layer model. The first layer the city's housing infrastructure - represents the properties of urban housing; the second layer - free human agents - represents individual citizens and reflects their migratory movements (Portugali and Benenson, 1995).

Individual free agents in the MA model have the ability to estimate the state of the city on its two layers and behave in accordance with information regarding three levels of urban organization:

- The individual;

- The local - referring to the characteristics of neighborhood and state of the neighbors;

- The global - referring to the state of the whole city.

Based on this information, individual agents immigrate into the city, occupy and change residential locations there, and leave the city when conditions become unsatisfactory.

Free agents are characterized in MA models by their economic status and cultural identity. Utilizing a series of agent-based models, we were able to show the emergence of different forms of cultural and economic segregation. Moreover, by introducing explicitly the ability of the agents to evolve we have demonstrated the emergence of new socio-cultural groups in the city space (Portugali et al., 1994; 1997; Benenson and Portugali, 1995; Portugali and Benenson, 1994; 1997). In the following, these results are reviewed and expanded in two directions. First, the theoretical MA model is implemented in a real-world GIS environment. Second, the general representation of cultural identity by means of a "cultural phenotype" is introduced and studied.

\subsubsection{Agent-based simulations of economic interactions between individuals}

In the economic version of the MA model, the relationships between individuals and their neighbors and neighborhood are based on those 
individuals' economic status and the value of their houses. Two implementations of an economic MA model are considered below, the abstract one, where a lattice of cells serves as the housing layer and the GIS-based model with a map of the houses and streets is taken as the background. While the abstract version of the model lies in the mainstream of CA and MA simulations, the purpose of the GIS-based version is to account for the heterogeneity of the spatial structure of the real-world city and to implement the MA model as an operational tool.

\section{Sub-model of the housing infrastructure} Cellular Automata representation of housing The infrastructure of an abstract version of the MA model is a square lattice of cells, which symbolize houses. Each house $H_{i j}$ can be either occupied by one individual agent or remain empty. A $5 \times 5$ square with $H_{i j}$ in the center is considered as the neighborhood $U\left(H_{i j}\right)$ of house $H_{i j}$. Houses differ in their value $V_{i j}$. For each time step, the value of the house is determined anew. When an agent A occupies house $H_{i j}$, its value $V_{i j}$ is updated in accordance with A's economic status $S_{\mathrm{A}}$ (see below) and the average value of the neighboring houses. When a free agent leaves house $H_{i j}$, and the latter remains unoccupied, its value decreases at a constant rate.

The GIS map of houses and streets as a background Many high-resolution GIS-based maps have recently become available. These maps make it possible to substitute the abstract cellular space background of the model by the housing structure of the real-world city. They, thus, facilitate the study of the role of housing heterogeneity and varying neighborhood structure in urban dynamics. The GIS version of the economic MA model used by us is based on a digital street and housing map of a section of the Tel-Aviv metropolitan area at 1:500 scale. Each house is represented by two variables, namely, the value of the house and its capacity (number of apartments). As above, the value of the house is updated at every time step in accordance with the mean status of its residents and the value of the neighboring houses. Two among various possible definitions of the neighborhoods are considered. Scenario A (reminiscent of the CA-type city) takes into account only the distances between houses; scenario $B$ accounts for the heterogeneity induced by the city's street network as well. For scenario A, the neighborhood $U(H)$ consists of all the houses located at a specified distance from $H$. In scenario B, it is assumed that the decisions made by agents are influenced by the condition on their side of the street only. In order to implement this suggestion, the neighborhoods of houses located along several specific streets were restrained to all those houses situated at the same side.

Dynamics of the economic status of free human agents

The dynamics of the economic status $S_{\mathrm{A}}^{t}$ of agent A occupying house $H$ is described in a simple logistic way:

$$
S_{\mathrm{A}}^{t+1}=\left(R_{\mathrm{A}} \cdot S_{\mathrm{A}}^{t} \cdot\left(1-S_{\mathrm{A}}^{t}\right)-m \cdot V_{H}^{t}\right) /\left\langle V^{t}\right\rangle_{\text {city }},
$$

where $R_{\mathrm{A}}$ is an individual rate of economic growth and does not depend on $t, m \cdot V_{H}^{t}$ is a "mortgage payment" and $\left\langle V^{t}\right\rangle_{\text {city }}=\sum_{k l}\left\{V_{k l}^{t} \mid k, l \in[1, M]\right\} /$ $(M \times M)$ is a mean value of houses over the city.

The local economic information $P^{t}$ available to individual agent $\mathrm{A}$, occupying a house $H$, is given by the economic status of A's neighbors and their houses' values in $U(H)$. For CA representation of the housing $P_{i j}^{t}$ is a mean of the status of the neighbors occupying the houses within $U\left(H_{i j}\right)$ and the values of the unoccupied neighboring houses. For the GIS-based version $P^{t}$ is an average of the mean status of agents located in the house $H$ and in the neighboring houses.

The migration decision of agent $A$ depends on the absolute value of the difference $\mathrm{SD}_{\mathrm{A}}$ between A's status $S_{\mathrm{A}}^{t}$ and $P^{t}$, namely, on $\mathrm{SD}_{\mathrm{A}}^{t}=\left|S_{\mathrm{A}}^{t}-P^{t}\right|$. Below we call $\mathrm{SD}_{\mathrm{A}}$ a local economic tension of an agent $\mathrm{A}$ at location $H$. 
The average $\left\langle V^{t}\right\rangle_{\text {city }}$ of housing values over the city gives the global economic information available to each individual agent at iteration $t$. According to (6), it feeds back the description of the agent's status dynamics.

\section{Trade off between migration and changes}

in an individual's status

According to the model's flowchart (Fig. 1), at every time step, each free agent $\mathrm{A}$ in the city decides whether to move from or to stay at its present location. It is suggested that for an agent A, located currently at $H$, the probability of leaving its current location increases monotonously with an increase in an individual's economic tension $P^{t}$. The probability of occupying an empty house $\mathrm{G}$ when it is the only possible choice decreases monotonously with an increase in individual's estimation of the economic tension at $G$ and to repeat, does not depend on the previous location of that individual. For details of choice process involving several vacant houses, see Portugali et al., (1997).

The conjunction between individual, local, and global factors can lead an individual agent A "to decide" not to reside within the city in spite of the high economic tension at its current location. The reason for this decision might be a lack of attractive vacant houses in the city. In this case either the economic tension continues to increase, while it can be occasionally resolved by the agent leaving the city with probability $p_{U}$. Insolvent agents, whose economic status has dropped below zero, leave the city eventually.

\section{Immigration}

At every time step, a constant number of individuals try to enter the city from without and to occupy a house. The economic status $S_{\mathrm{I}}$ and growth rate $R_{\mathrm{I}}$ of each immigrant I are assigned

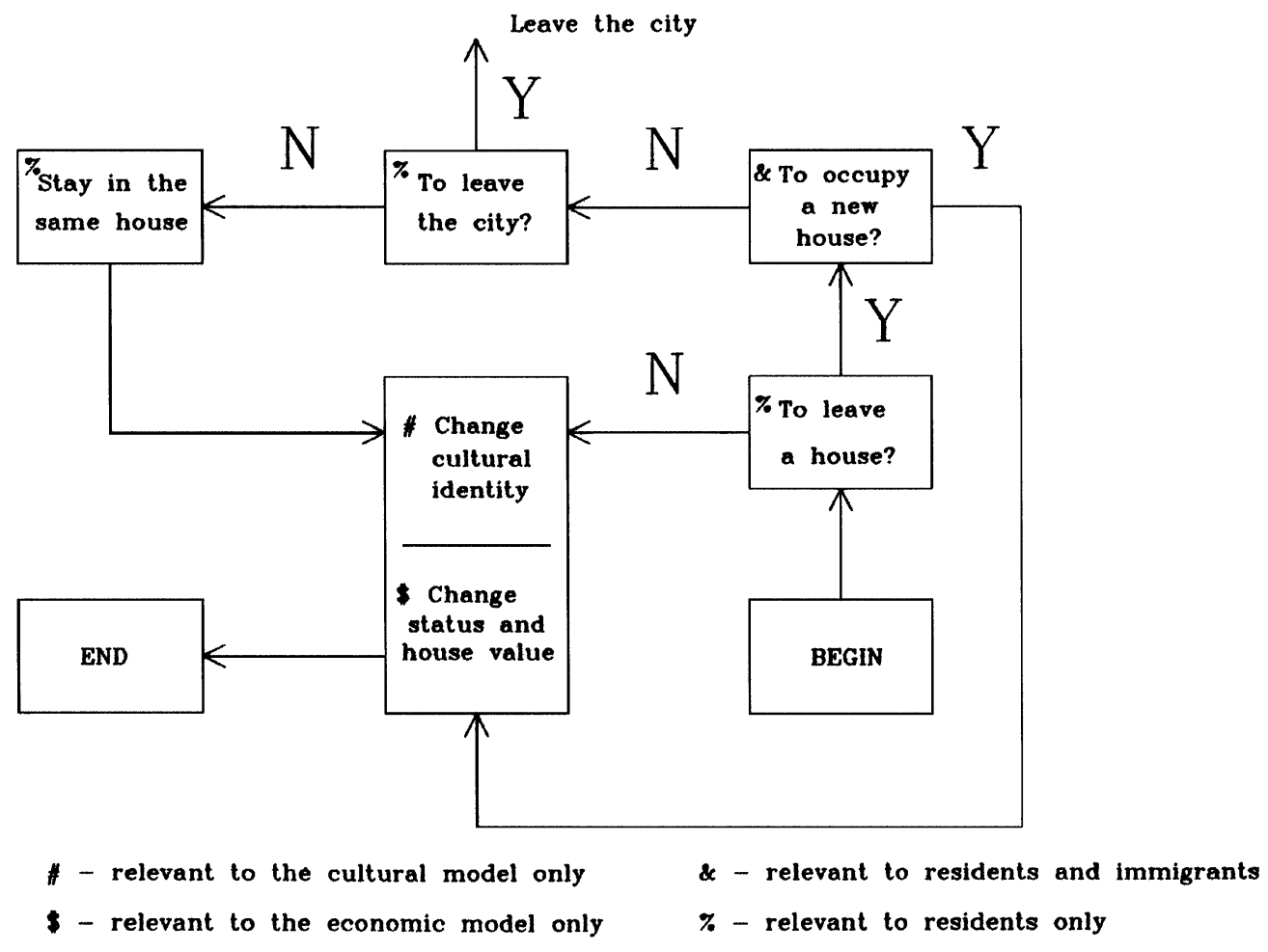

FIGURE 1 Consequence of agent's decision. 
randomly and independently. The distribution of immigrants' status is normal, with a mean equal to the instantaneous agents' mean status over the city at previous time step and constant CV. The distribution of $R_{\mathrm{I}}$ is also normal and independent of $t$.

Global consequences of individuals,

economic interactions

Cellular Automata representation of housing The city economic structure is described in the model by means of the distribution of housing values, the distribution of the agent's status and the distribution of the status growth rate. Irrespective of their initial state these distributions converge to smooth and correlating patterns during several hundred iterations (Fig. 2(a)). After initial period of rapid changes, they evolve very slowly, with rich/poor domains moving slowly and stochastically throughout the urban area (Fig. 2(b)).

GIS map background For scenario $\mathrm{A}$, the gradient of the housing values and individual status is established after hundred iterations
(Figs. 3(a) and 3(b)). Subsequently it varies slowly in the manner demonstrated for the cellular version of the model. Scenario B was tested against one wide street in the city. Referring to Fig. 3(c), we see that the resulting distribution of the housing values is discontinuous, with abrupt disparities between different sides of "Red" Street. "Red" Street prevents penetration of the agents of high (low) economic status into the quarters on each of its respective sides, thus constraining the variability of the steady distribution of the housing values along the entire length of the street. Comparing to $\mathrm{CA}$ version, the rigid street and housing patterns restrict variability of the population distribution at the slow stage of the city dynamics.

\subsubsection{Individual cultural identity and simulation of cultural interactions between agents}

Formal representation of the non-economic features of an individual should differ from one-dimensional

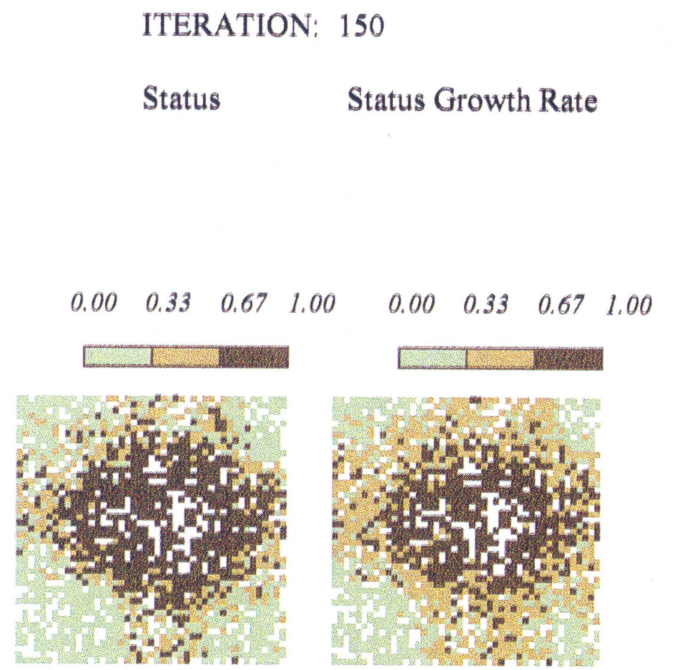

(a)
ITERATION: 3000

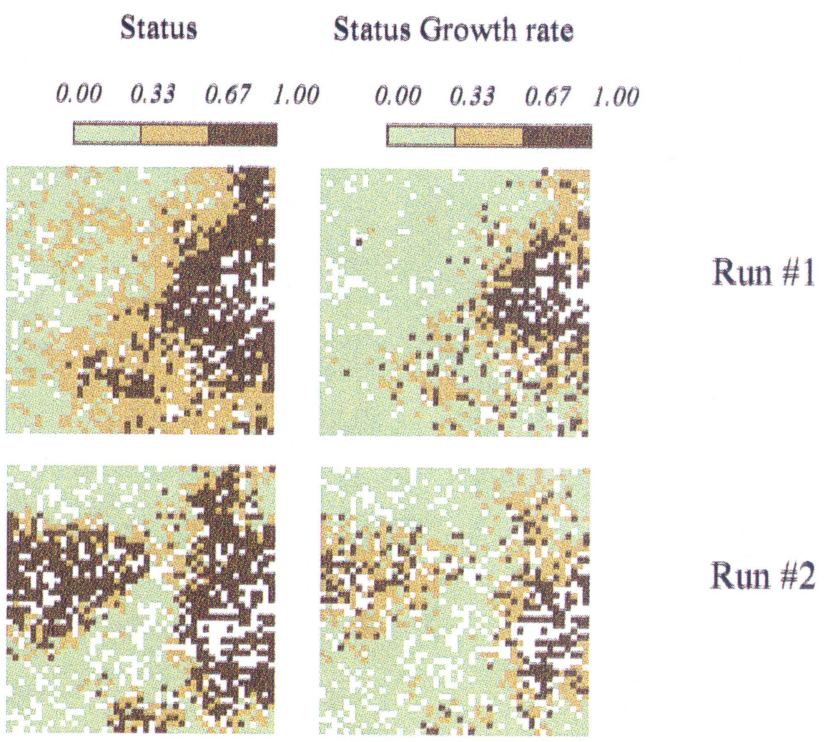

(b)

FIGURE 2 Economic MA-model: population distribution according to economic status and status growth rate. (See Color Plate I.) 


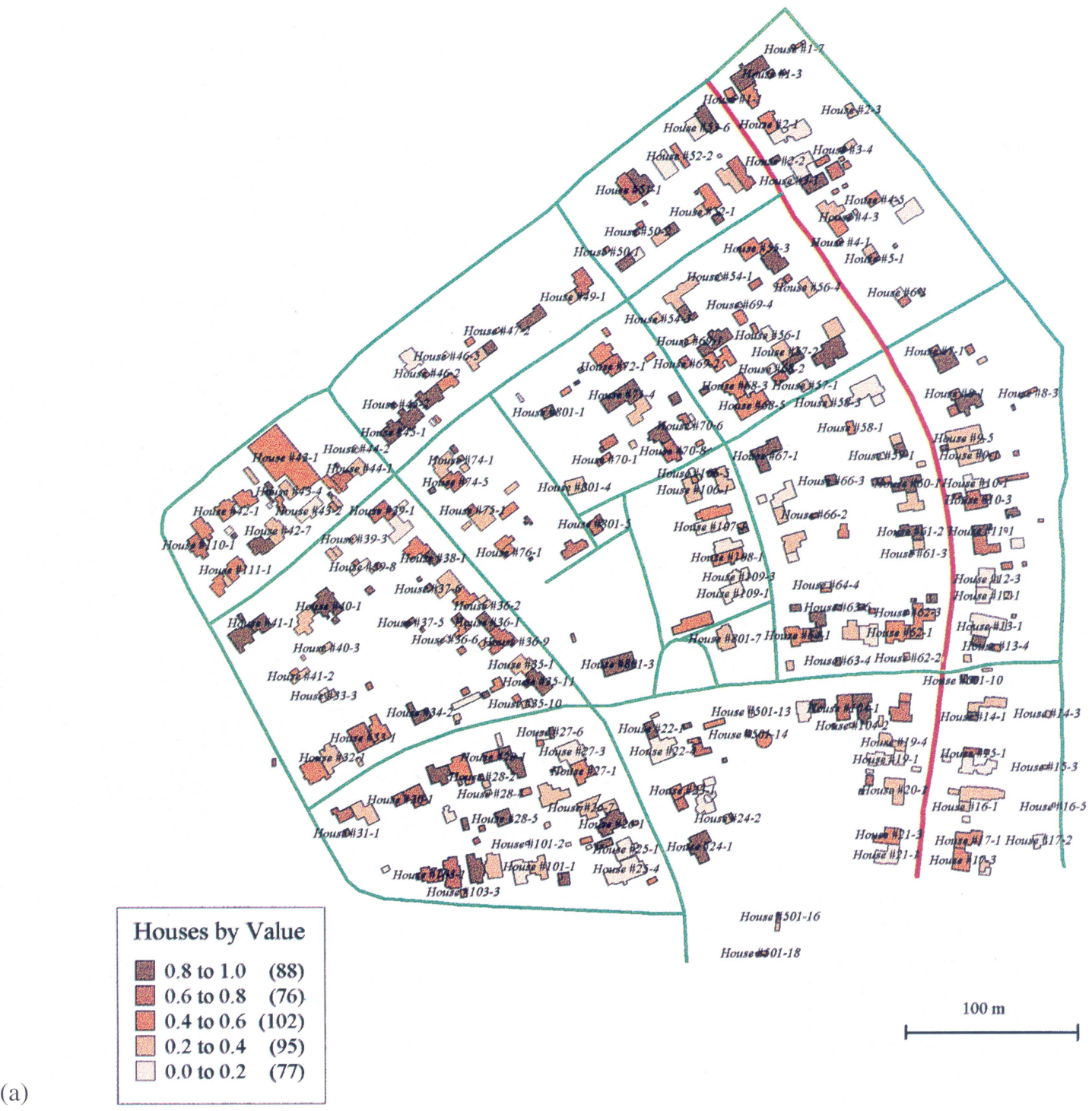

FIGURE 3(a) Initial distribution of house values is random, uniform on $[0,1]$. (See Color Plate II.)

quantitative representation of economic characteristics above. This is especially true regarding individual's cultural identity, which representation should capture the multi-dimensional, nominal and qualitative character of the latter. Suggested below "cultural code" is analogous to a genetic code, which partially pre-programs an individual's behavior when creating groups or societies. In the genetics of qualitative features as well in artificial life studies, it is common to represent an individual's genotype by a high-dimensional binary vector of traits (Banzhaf, 1994; Kanenko, 1995). The cultural code is also binary and, in contrast to genetic restrictions, changing in response to the agent's interactions with 


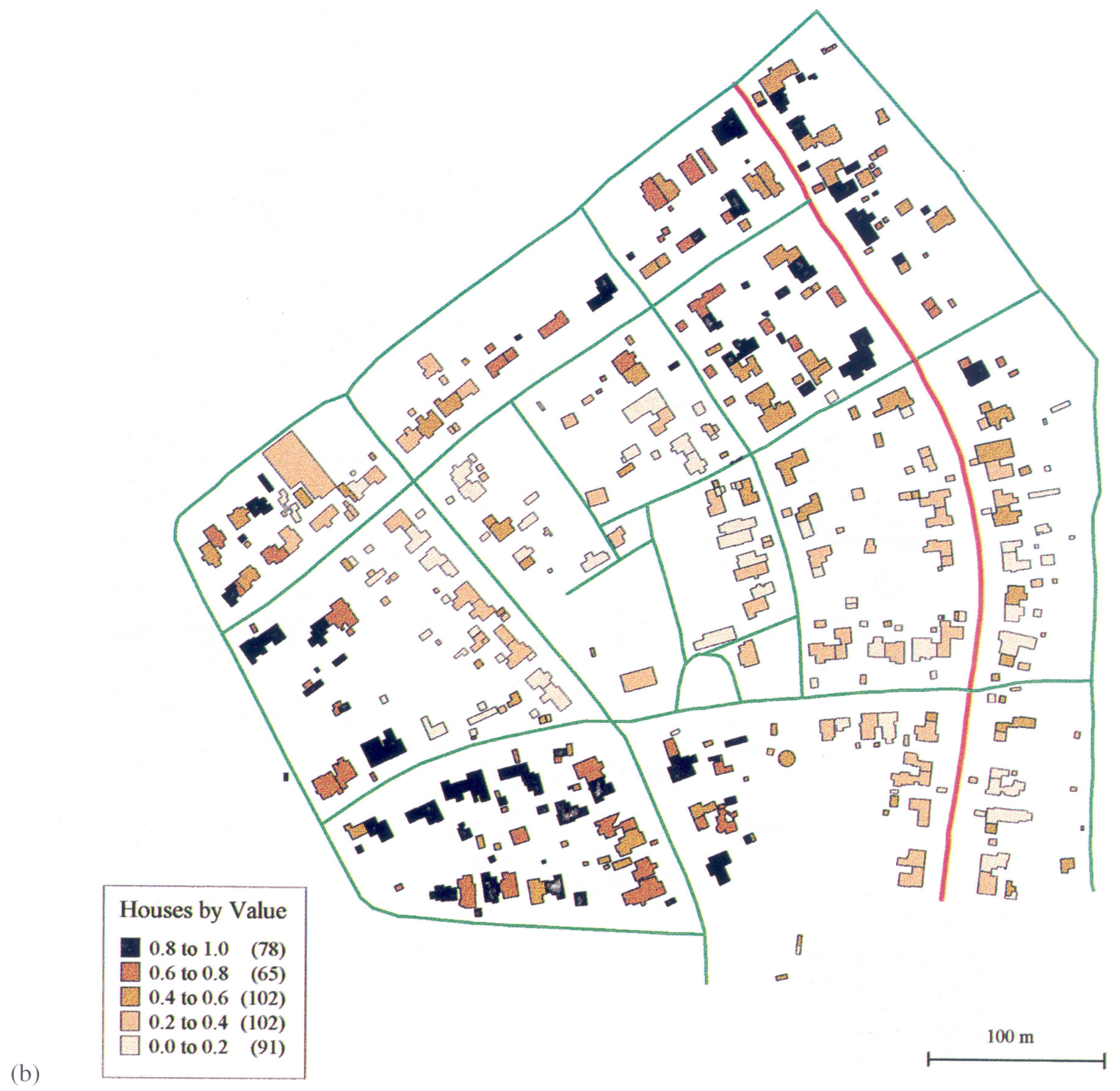

FIGURE 3(b) Distribution of house values at $T=200$ for scenario A. (See Color Plate III.)

the neighbors, the neighborhood, and the city as a whole. In consequence, individual's residential behavior also changes.

Formal representation of the cultural code and the dynamics of an agent's cultural identity

The cultural identity of an agent A is described by the $K$-dimensional Boolean cultural code
$C_{\mathrm{A}}=\left(c_{\mathrm{A}, 1}, c_{\mathrm{A}, 2}, c_{\mathrm{A}, 3}, \ldots, c_{\mathrm{A}, K}\right)$, where $c_{\mathrm{A}, k} \in\{0,1\}$, $k=1,2,3, \ldots, K$. Consequently, individuals of $2^{K}$ different cultural identities might exist in the same city. The difference $\rho$, between agents $\mathrm{A}$ and $\mathrm{B}$, according to their cultural identities is measured by

$$
\rho\left(C_{\mathrm{A}}, C_{\mathrm{B}}\right)=\sum_{k}\left(c_{\mathrm{A}, k} \mathrm{XOR} c_{\mathrm{B}, k}\right) / K
$$




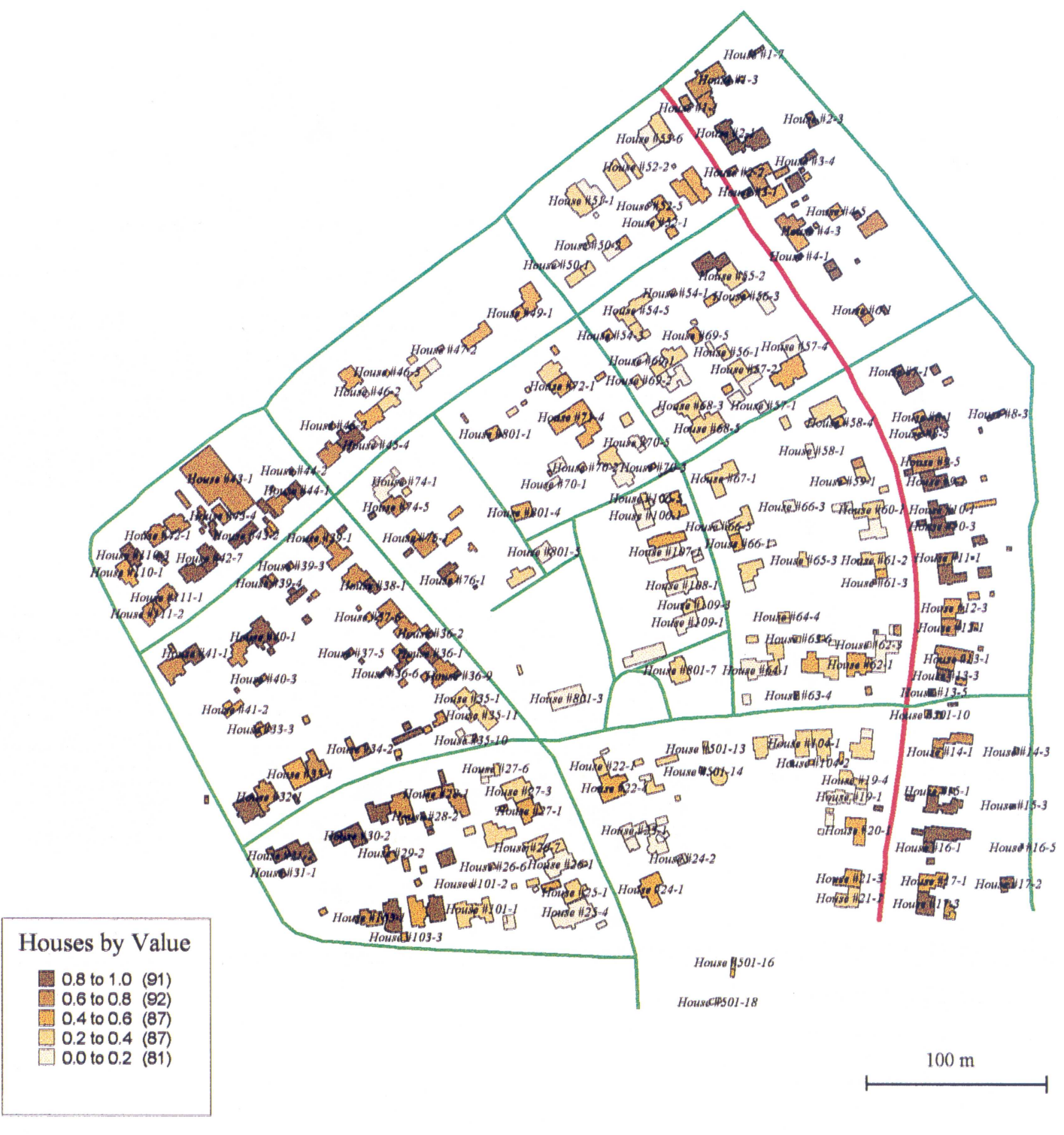

(c)

FIGURE 3(c) Distribution of house values at $T=200$ for scenario B. Neighborhoods are defined as in A, but constrained by the "Red" Street. (See Color Plate IV.)

In a manner similar to the economic version of the model, an agent behaves in line with the available individual, local, and global cultural information. The representation of local cultural information is related to the notion of local spatial cognitive dissonance, introduced by Portugali and Benenson (1995) and Haken and Portugali (1995). Applying their general definition to the multi-dimensional presentation of cultural identity, the local spatial cognitive dissonance $\mathrm{CD}_{\mathrm{A}}$ of agent $\mathrm{A}$ is defined as an average of the differences between A's cultural identity and the cultural identities of its neighbors, given by (7). As in the economic model, the higher the local dissonance of $\mathrm{A}$, the higher the probability 
that A will leave its current location and try to occupy the alternate one. The probability of locating at an empty house $\mathrm{G}$ decreases with the increase in the estimate of potential spatial cognitive dissonance at $\mathrm{G}$.

The influence of the global structure of the city on an individual's residential behavior increases in the model with a rise in the level of residential segregation. The global cultural information $\mathrm{GD}_{\mathrm{A}}$ available to a free agent $A$ is, thus, determined in the model by the value of Lieberson's (1981) segregation index $\mathrm{LS}_{X}$, expressed as a probability of a member of group $X$ located at house $H$ to meet a member of its own group within $U(H)$. Visually, values of $\operatorname{LS}_{X}$ below 0.3 correspond to a random distribution of the agents belonging to group $X$, while values above 0.8 correspond to one or several domains occupied almost exclusively by these individuals. Formally, for agents of identity $C_{\mathrm{A}}$,

$$
\mathrm{GD}_{\mathrm{A}}^{t}=\max \left\{0,\left(\mathrm{LS}_{\mathrm{A}}^{t}-\mathrm{LS}^{*}\right)\right\} /\left(1-\mathrm{LS}^{*}\right),
$$

where $\mathrm{LS}^{*}$ is the threshold value of LS that corresponds to the visually segregated pattern.

Local and global information influence an agent's cultural identity in alternative ways. High local cognitive dissonance $\mathrm{CD}_{\mathrm{A}}^{t}$ forces agent $\mathrm{A}$ to change its cultural identity. In contrast, a high level of segregation $\mathrm{GD}_{\mathrm{A}}^{t}$ of agents having an identity $C_{\mathrm{A}}$ forces $A$ to preserve its current identity. An agent A's sensitivity to local cognitive dissonance $L_{\mathrm{A}}$ and to global segregation $G_{\mathrm{A}}\left(L_{\mathrm{A}}, G_{\mathrm{A}} \in[0,1]\right)$ are properties inherent to A and independent of $t$.

If an agent $\mathrm{A}$ is forced to occupy its current location in spite of high cognitive dissonance, then its cultural identity can be changed. This occurs in the model when the local tendency of an agent to vary exceeds the global tendency to preserve its current identity, that is when $L_{\mathrm{A}} \cdot \mathrm{CD}_{\mathrm{A}}^{t}>G_{\mathrm{A}} \cdot \mathrm{GD}_{\mathrm{A}}^{t}$. If the latter is true, then the probability that the $i$ th component of $C_{\mathrm{A}}$ will be changed is proportional to the absolute value of the difference between the fraction of the $i$ th component among A's neighbors and its value (zero or one) for A. Additionally, "mutation" of the cultural code is possible, with probability $r$ per component, although only one component of the cultural code can be changed per iteration.

\section{Immigration}

As the economic version of an MA model, at every time step a constant number of individuals try to enter the city and occupy a house there. The cultural identity of the immigrants is assigned at random, in proportion to the current fractions of agents having each of the $2^{K}$ possible identities.

\section{Trade off between migration and change of} an individual's cultural identity

An inherent source of the cultural dynamics in the model is the mutation process that prevents it from becoming culturally homogeneous. An individual agent located in a heterogeneous neighborhood of non-zero dissonance, either succeeds in changing residence or fails. If it fails, the agent either changes identity towards the "modal" identity of its neighbors (Fig. 1) or preserves its current identity due to the high level of segregation of agents of similar identity in the city. Unlike the changes in the one-dimensional economic status, a change in cultural identity does not necessarily decrease the cultural diversity of the city. To illustrate that, consider the agents located at a boundary between two segregated groups of individuals of $(0,0,0, \ldots, 0)$ and $(1,1,1, \ldots, 1)$ identities. It is highly probable that the identity of an agent $(0,0,0, \ldots, 0)$ will change to one having unit at one of the components, say, to $(1,0,0, \ldots, 0)$, and thus will differ from the identities of the agents of both groups.

\section{Global consequences of individuals' cultural interactions}

The aim of the cultural version of the MA model is to examine the process of socio-cultural segregation and emergence in city, the inhabitants of which can vary in their cultural identity according to high number of traits. To qualify as a new sociocultural entity, a group of individuals sharing the same cultural identity must fulfill simultaneously 
two conditions (Portugali et al., 1997):

- At the local level, most of the group members should be located within culturally uniform neighborhood;

- At the global level, the number of group members and their spatial segregation have to be sufficiently high.

Our previous study demonstrates three types of persistent residential dynamics in the city populated by the agents, whose cultural identity is represented by quantitative characteristic, continuously varying on $[0,1]$ (Benenson and Portugali, 1995). One type can be termed a "random" city, another a "homogeneous" city, in which almost all of the agents belong to the cultural group of either 0 - or 1 -agents, and the third type is characterized by three coexisting segregated groups, whose members have close to 0-, 1- and 0.5-identities. For the latter case, the 0.5 -group is emerging and self-organizing during the city and agents' coevolution (Benenson and

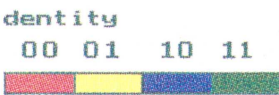

$$
\mathrm{K}=2, \mathrm{~T} \sim 500
$$
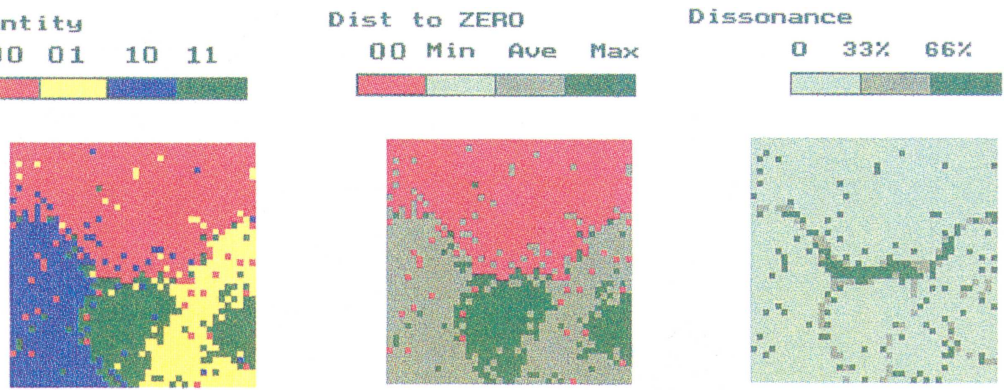

(a)

I dent ity

More than 4

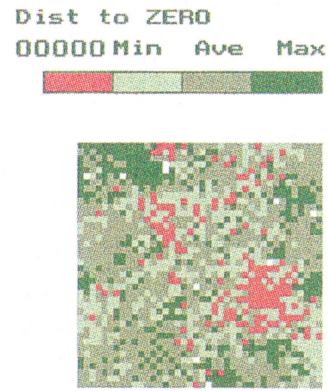

Dissonance o $33 \% 66 \%$

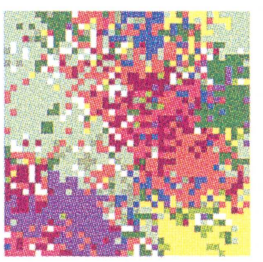

Portugali, 1995; Portugali and Benenson, 1997; Portugali et al., 1997). In the following section, the phenomenon of multiple and recurrent sociocultural emergence is investigated based on newly introduced multi-dimensional and qualitative individual's cultural code. The three-type typology of urban residential dynamics can be applied with a multi-dimensional cultural identity as well, and the set of parameters entailing the coexisting segregated groups is used below to investigate the model. The three questions responded to are: What are the number and level of segregation of each emerging (if ever) cultural entity? Are these groups fixed or do they vanish with time? What is their life history? The system behavior is investigated below for the case of up to a five-dimensional cultural code.

Presentation of the urban patterns

A city's cultural pattern is presented by means of three kinds of maps (Fig. 4). The first represents a

$$
\mathrm{K}=5, \mathrm{~T} \sim 500
$$


distribution of the agents' cultural identity, with each identity marked by its own color. This map is the most detailed of the three, but its method of presentation inconvenient for $K>2$ in view of the high number and nonlinear ordering of identities. The second type of map is that of the difference $\rho\left(C_{\mathrm{A}}, C_{0}\right)$ between the identity $C_{\mathrm{A}}$ of agent $\mathrm{A}$, occupying house $H$, and some identity chosen a priori, say, $C_{0}=(0,0,0, \ldots, 0)$. This map shows those effects that do not depend on $K$; its disadvantage lies in the fact that for several different identities, $C_{\mathrm{A}}$ can differ equally from the identity selected for comparison. The third map is that of a distribution of the cultural cognitive dissonance of the residents (Portugali et al., 1995) and represents the domains of the most intensive changes either in population distribution or in the cultural identity of the model agents. The fraction of the agents that want to leave the city, which is defined by the overall mean value of the cultural dissonance, is used below as an indicator of its overall instability. The presented results do not depend on the initial distribution of the agents in the city.

Model dynamics for low-dimensional cultural codes $(K=2)$ The case $K=2$ corresponds to our previous analysis of residential segregation between a small number of cultural groups (Portugali et al., 1994). The city dynamics in that case entails a rapid self-organization of two to four cultural identities within a few segregated patches. Here, the boundaries between the homogeneous patches remain areas of instability, with intensive exchange of individuals (Fig. 4(a), compare to Portugali et al., 1994).

Let us skip the intermediate cases of $K=3,4$ and proceed to $K=5$.

Model dynamics for a high-dimensional cultural code $(K=5)$ The number of possible identities for $K=5$ equals $2^{5}=32$. In a way similar to the case of $K=2$, the boundaries between the homogeneous domains and the heterogeneous domains, occupied by the agents of varying identities, remain areas of instability. The agents located there either try to leave their houses or change their cultural code. None of the properties of the specific cultural identities can be predicted in the long run, but it is still possible to understand and predict the following properties of the population distribution in the model city:

(1) The persistent city structure is characterized by a mixture of spatially homogeneous and heterogeneous domains. The former, whose populations form cultural entities, covers about half of the city's area for $K=5$ (Fig. 4(b)). The distribution of cultural differences $\rho\left(C_{\mathrm{A}}, C_{0}\right)$ between the agents with cultural code $C_{\mathrm{A}}$ and the "basic" cultural identity $C_{0}=(0,0,0,0,0)$ is self-organizing as well (Fig. 4(b)).

(2) A limited number of cultural entities can exist in the city simultaneously (Figs. 4(b), 5(a)).

(3) The life-span of a socio-cultural entity is finite; newly emerging entities replace each other in the city space. About 20 percent of the entities persist in the city for not less than 10 iterations and about 10 percent exist for not less than 25 iterations (Fig. 5(b)).

The global model dynamics can be explained on the basis of the distribution of cultural differences, presented in Fig. 4(b). This distribution has two contradictory characteristics. First, the difference $\rho\left(C_{\mathrm{A}}, C_{0}\right)$ increases with the increase in the distance of agent $\mathrm{A}$ from the location of the agents having cultural code $C_{0}$. Second, the multi-dimensionality and, hence, non-linear ordering of the identities implies the recurrent emergence of adjacent entities $C_{\mathrm{A}}$ and $C_{\mathrm{B}}$, that differ equally and significantly from $C_{0}$ and between themselves $\left(\rho\left(C_{\mathrm{A}}, C_{0}\right) \sim \rho\left(C_{\mathrm{B}}\right.\right.$, $\left.\left.C_{0}\right) \sim \rho\left(C_{\mathrm{A}}, C_{\mathrm{B}}\right)\right)$. It can be observed, for instance, at the bottom of Fig. 4(b), where the boundary between the identities, which are represented in violet and yellow (first map from the left), is an area of high dissonance between them (right map), while both of them differ from $C_{0}$ (middle map). This phenomenon implies non-monotonous dependence of the index of the city's instability, represented by the mean fraction of the agents that want to leave the city, on the number of coexisting entities (Fig. 6). According to the Fig. 6, with an increase in the number of entities, the city's instability first decreases. With a further increase in the number of entities, the emerging cultural entities occupy the 


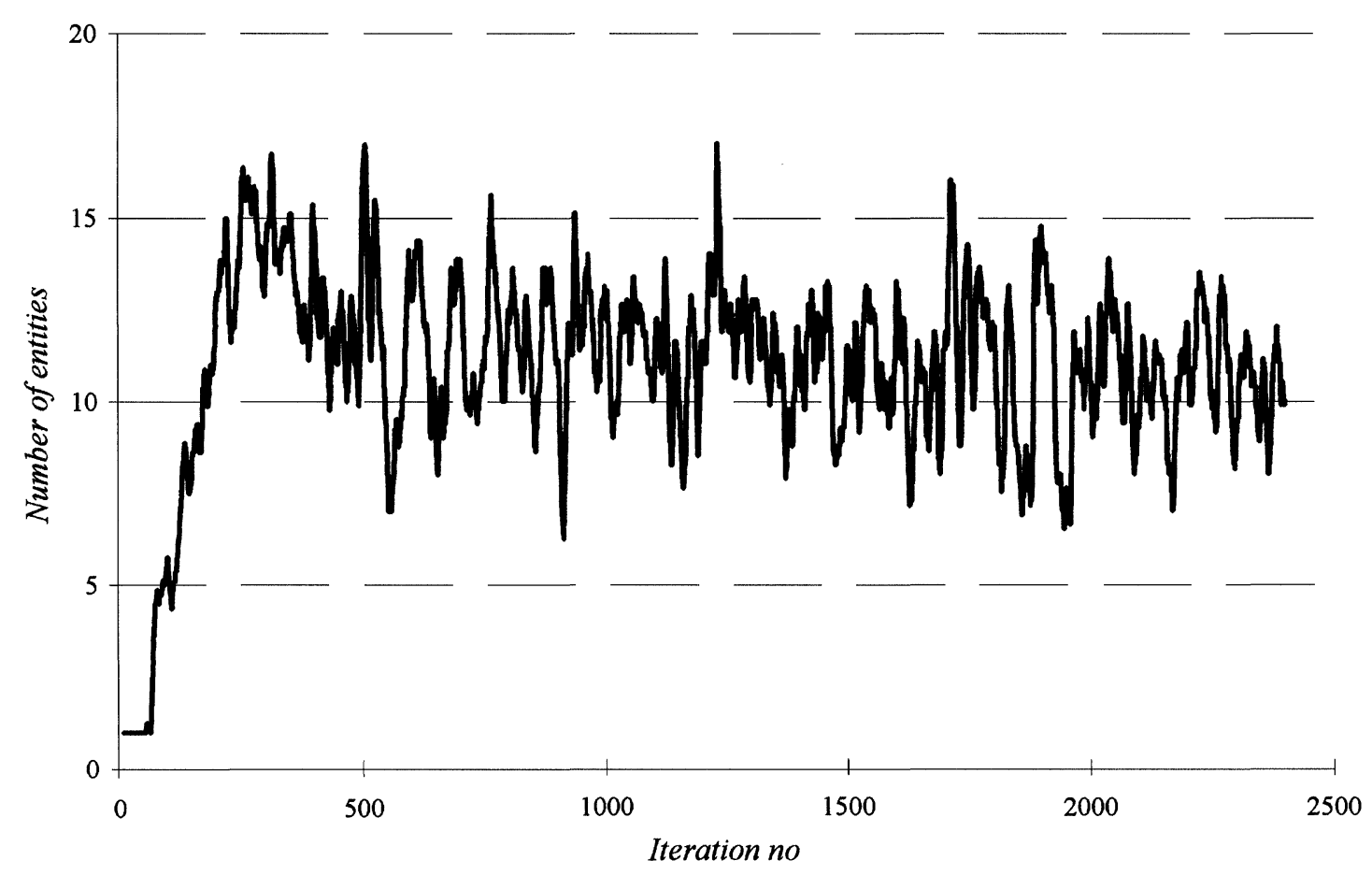

FIGURE 5(a) Dynamics of the number of cultural entities for $K=5$.

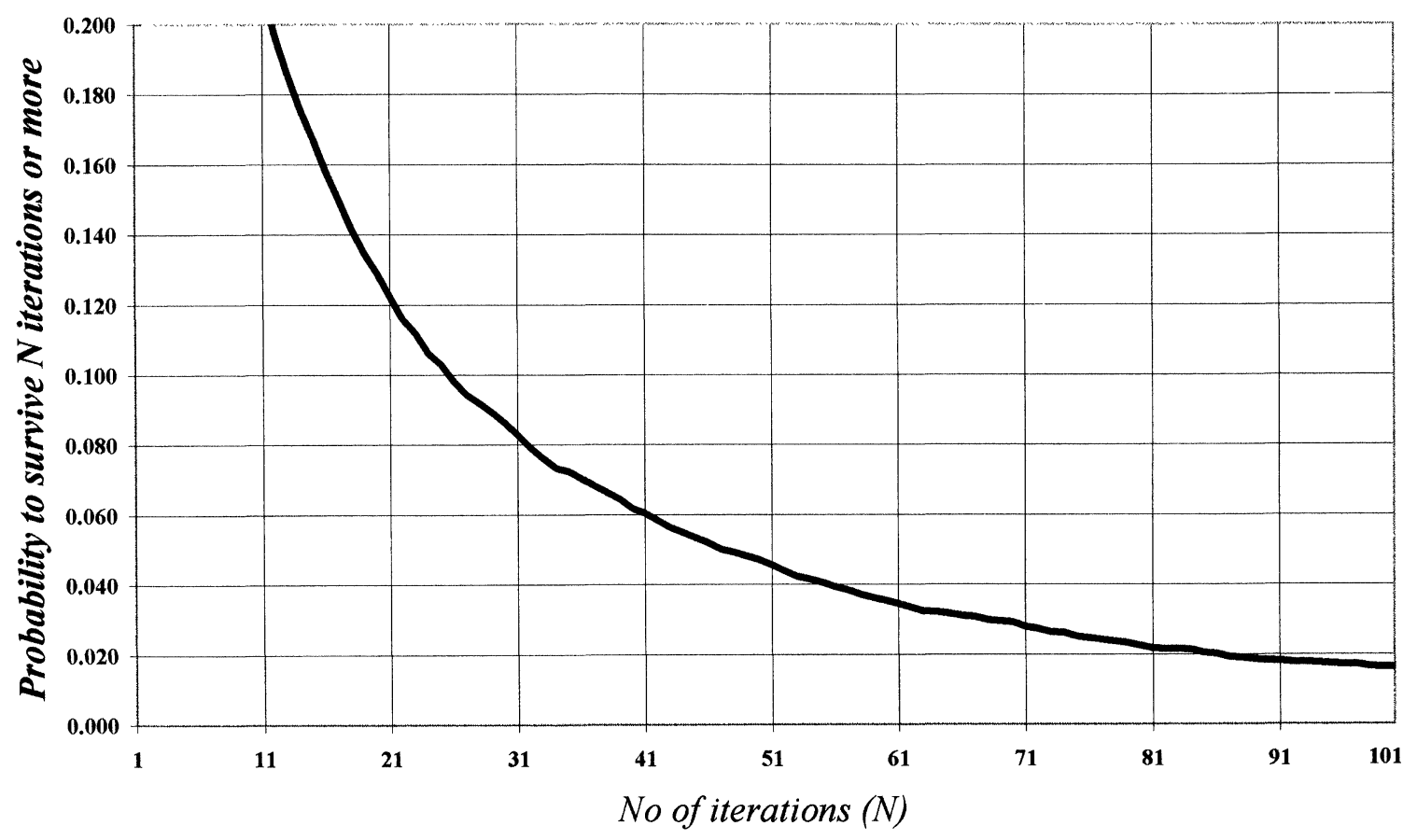

FIGURE 5(b) Survival function for cultural entity. 


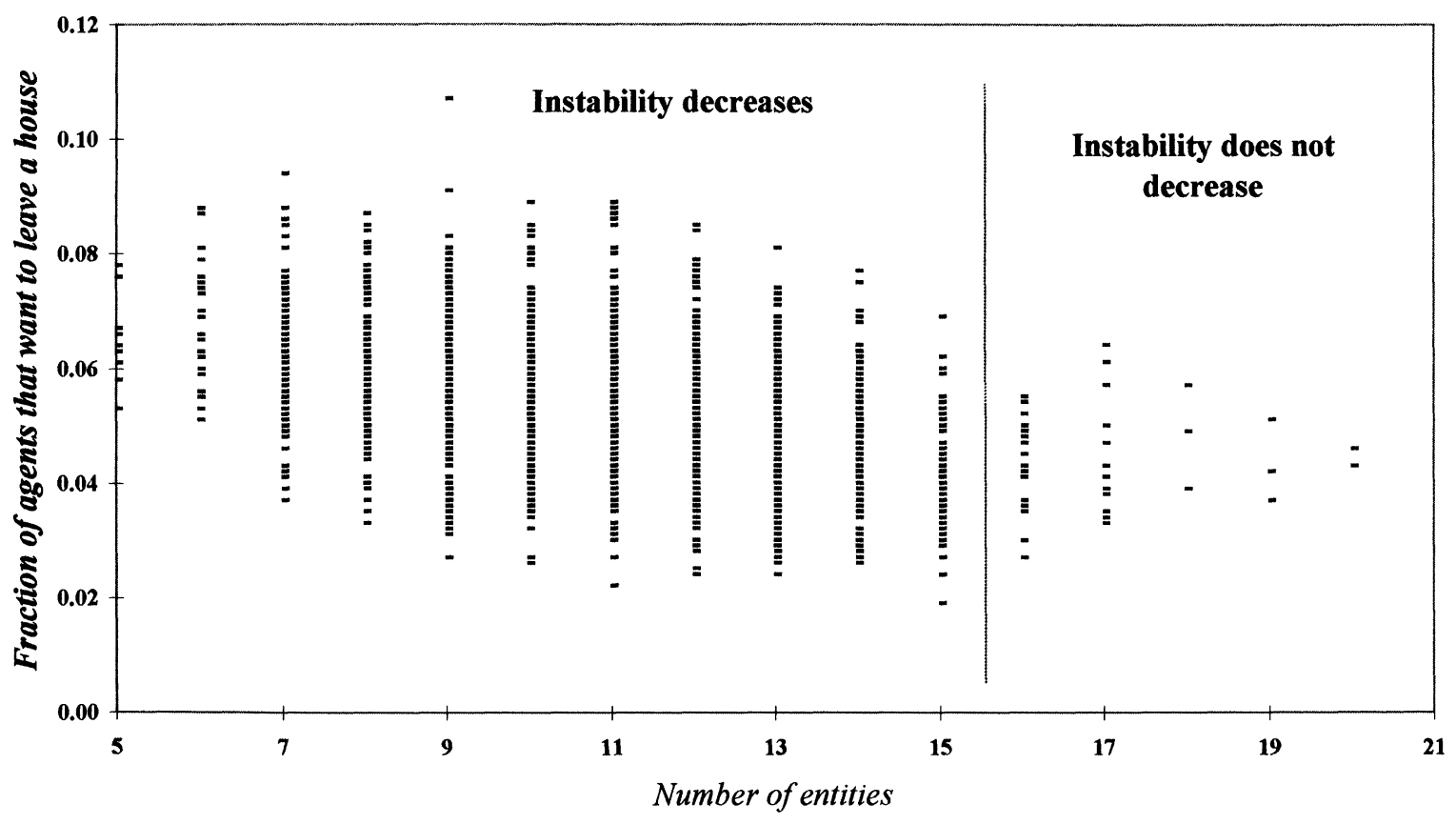

FIGURE 6 City's instability vs number of entities.

bulk of the territory, while the heterogeneous areas vanish. In such circumstances contiguity between contrasting entities is inevitable. The self-organizing boundaries between them then sharpen and expand and the city's instability increases once again (Fig. 6). In consequence, we can say that urban instability is limited from below, and that the model city itself is self-organizing and evolving towards a critical structure that preserves its internal capacity to changes.

To conclude, the micro-interactions at the agents' and houses' levels entail recurrent selforganization of population groups at the macrolevel, according to both economic and cultural characteristics. The resulting persistent residential distribution depends on the nature of the characteristic we are interested. Continuously varying economic characteristics induces smooth residential distributions, which is characterized by low level of instability and consequently, by slow temporal changes. Qualitative and multi-dimensional "cultural code" entails self-organization of the critical population distribution, which is character- ized by the preservation of a significantly high level of instability and, therefore, by the recurrent emergence and disappearance of cultural groups. Concerning the applied aspect, the GIS-based economic version of the model can be considered as a first step towards the operational implementation of a MA simulation approach.

\section{BACK TO INTEGRATION, BASED ON THE HIERARCHY OF MODELS OF CITY COMPONENTS}

Let us compare different model approaches according to their spatial and temporal resolutions. The spatial unit of the ecological model is the entire city. For the regional approach, a model unit represents a relatively large urban region. The spatial unit of the CA model is of intermediate size and determined by the degree of homogeneity that can be achieved when partitioning a city's territory according to a given classification of land usage. The spatial unit of the MA model is the smallest, 
defined by dimensions of the separate house or compact group of houses.

The problem of which time scale fits the given approach is more complicated. In general, the model's time scale is defined by the temporal resolution of the available parameter estimates. If, for instance, parameters are estimated for monthly intervals then, obviously, the model solutions describe the monthly dynamics of the system. Consequently, the issue of time scale is a problem of the selection of an appropriate temporal unit for the estimation of the parameters and the interpretation of the results. Regarding ecological models, selection of the time unit is rather arbitrary because we assume we can obtain a complete or almost complete description of the model behavior for all possible sets of parameters. The large number of non-uniformly interacting components of the regional model make it impossible to obtain general results regarding the solutions' behavior. Moreover, the very concept of regional modeling eventually combines processes that occur at different time scales. For example, yearly to decade varying land uses, monthly to yearly varying inter-city migration flows, monthly varying employment market or weekly varying transportation flows are all considered in the common framework of an Integrated Urban Model. Spatially, the statistical or administrative divisions we are usually forced to utilize, provide a framework for averaging - rather than the carriers - of the parameters employed in regional models. As a result, quantitative relations between the parameters, partially estimated at different time resolutions or partially substituted by some "likelihood" values, determine the behavior of the regional model. This can make sense in the short term, but becomes pointless if we pretend modeling a system undergoing qualitative modifications and bifurcations. To avoid this discrepancy, we can constrain the model to the processes that occur at the same time scale only. According to the synergetics paradigm, these processes, if hypothesized properly, are not many; we can, therefore, hope that the dimensions of the constrained model will be sufficiently low to enable estimation of the param- eters and the classification of the solution. The proper selection of the processes in regards to the time scale depends greatly on the system's specificity, and no other confirmation of certain preferences can be obtained by any means other than the operational "Do it!" From this point of view, the results of the CA and MA model approaches are rather encouraging. The former utilizes land-use dynamics as a process defined by substitutions between a limited number of the parcels' different states, which occur annually or perhaps rarely. The latter deals with the residential decisions that people pose to them more frequently. Both of these approaches demand a reasonably low number of parameters and generate self-organizing bifurcative dynamics - the CA model regarding the urban infrastructure and the MA model regarding urban residential distribution. In parallel, these approaches work with different but "adjacent" space resolutions. If we interlace the two, we can argue that the "fast" residential dynamics of the MA model should account for the outcomes of the "slower" CA model of land-use dynamics by functioning as the slow control parameters that define the location of residential areas, number of available dwellings, etc. An MA model feeds back information regarding qualitative changes in social and cultural structure of city population to the infrastructure level, since this information can influence the regulations governing transitions between land uses. It is an open question as to whether other levels of the urban hierarchy - in addition to those defined by land-use and individual residential behavior - should be considered separately. Trends in employment, birth and mortality, with their characteristic time scales should be examined in this respect. In general, the development of a hierarchical structure of models, each one dealing with urban processes at specific temporal and spatial scales, is a necessary step towards understanding and modeling urban dynamics. Separate models, each one describing processes at similar spatial and temporal scales, should be combined in a way that the variables of the slower and spatially less-detailed models serve as 
control parameters for those which are faster and more detailed. Detailed models, in turn, delegate pertinent information regarding qualitative changes to the higher hierarchical levels.

\section{References}

Allen, P.M., 1982, Evolution, modeling and design in a complex world, Environment and Planning B, 9, 95-111.

Allen, P.M. and Sanglier, M., 1979, A dynamic model of growth in a central place system, Geographical Analysis, 11, 256-272.

Allen, P.M. and Sanglier, M., 1981, Urban evolution, selforganization and decision making, Environment and Planning A, 13, 167-183.

Allen, P.M., Engelen, G. and Sanglier, M., 1986, Self-organizing systems and the 'laws of socio-economic geography', European Journal of Operational Research, 25, 127-140.

Anselin, L. and Madden, M. (eds.), 1990, New Directions in Regional Analysis. Integrated and Multi-regional Approach, Belhaven Press, London, 289 p.

Banzhaf, W., 1994, Self-organization in a system of binary strings, In: Brooks, R.A. and Maes, P. (eds.), Artificial Life $I V$, MIT Press, Cambridge, MA, pp. 109-118

Batty, M. and Longley, P., 1994, Fractal Cities, AP, London, $394 \mathrm{p}$.

Batty, M. and Xie, Y., 1994, From cells to cities, Environment and Planning B, 21, 531 - 548.

Benati, S., 1997, A cellular automata for simulation of competitive location, Environment and Planning B, 24, 205-218.

Benenson, I. and Portugali, J., 1995, Internal vs. external spatial information and cultural emergence in a self-organizing city, In: Frank, A.U. and Kuhn, W. (eds.), Spatial Information Theory: a Theoretical Basis for GIS, Lecture Notes in Computer Science, 988, Springer, Berlin, pp. 431-441.

Benenson, I. and Portugali, J., 1997, Agent-Based Simulations of a City Dynamics in a GIS Environment, In: Hirtle, S.C. and Frank, A.U. (eds.), Spatial Information Theory: a Theoretical Basis for GIS, Lecture Notes in Computer Science, 1288, Springer, Berlin, pp. 501-502.

Bertuglia, C.S., Occelli, S., Rabino, G.A. and Tadei, R., 1994, An integrated urban model, In: Bertuglia, C.S., Leonardi, G., Occelli, S., Rabino, G.A., Tadei, R. and Wilson, A.G. (eds.), Urban Systems: Contemporary Approach to Modelling, Croom Helm, London, pp. 178-191.

Conte, R., Hegselmann, R. and Terna, P., 1997, Social simulation - A new disciplinary synthesis in simulating social phenomen, In: Conte, R., Hegselmann, R. and Terna, P. (eds.), Lecture Notes in Economics and Mathematical Systems, 456, Springer, Berlin, pp. 1-17.

Couclelis, H., 1985, Cellular worlds: a framework for modeling micro-macro dynamics, Environment and Planning B, 17, 585-596.

Day, R.H., 1981, Emergence of chaos from neoclassical growth, Geographical Analysis, 13, 315-327.

Dendrinos, D. and Mullally, H., 1982, Evolutionary patterns of urban populations, Geographical Analysis, 13, 328-344.

Dendrinos, D. and Mullally, H., 1985, Urban Evolution: Studies in the Mathematical Ecology of the Cities, Oxford University Press, Oxford, $160 \mathrm{p}$.

Dendrinos, D. and Sonis, M., 1990, Chaos and Socio-Spatial Dynamics, Springer, NY, 184 p.
Durrett, R. and Levin, S.A., 1994, Stochastic spatial model. A user's guide to ecological applications, Phil. Trans. R. Soc. London B, 343, 329-350.

Engelen, G., 1988, The theory of self-organization and modeling complex urban system, European Journal of Operational Research, 37, 42-57.

Frankhauser, P., 1994, La Fractalite des Structures Urbaines, Collection Villes, Anthropos, Paris.

Haken, H., 1978, Synergetics, An Introduction, Springer, Berlin, $260 \mathrm{p}$.

Haken, H., 1993, Synergetics as a strategy to cope with complex systems, In: Haken, H. and Mikhailov, A. (eds.), Interdisciplinary Approaches to Non-Linear Complex Systems, Springer, Berlin, $280 \mathrm{p}$.

Haken, H. and Portugali, J., 1995, A synergetic approach to the self-organization of cities and settlements, Environment and Planning $B, 22,35-46$.

Hegselmann, R., 1996, Social dilemmas in lineland and flatland, In; Liebland, W.B.G. and Messick, D.M. (eds.), Frontiers in Social Dilemmas Research, Springer, pp. 337-361.

Itami, R., 1994, Simulating spatial dynamics: cellular automata theory, Landscape and Urban Planning, 30, 27-47.

Kanenko, K., 1995, Chaos as a source of complexity and diversity in evolution, In: Langton, C.G. (ed.), Artificial Life, An Overview, MIT Press, Oxford, pp. 163-177.

Lieberson, S., 1981, An asymmetrical approach to segregation, In: Peach, C., Robinson, V. and Smith, S. (eds.), Ethnic segregation in the cities, Croom Helm, London, pp. 61-82.

Maes, P., 1995, Modeling adaptive autonomous agents, In: Langlon, C.G. (ed), Artificial Life, An Overview, MIT Press, Oxford, pp. 135-162.

Murray, J.D., 1993, Mathematical Biology, 2nd edition, Springer, Berlin, $767 \mathrm{p}$

O'Neil, W.D., 1981, Estimation of logistic growth and diffusion model describing neighborhood change, Geographical Analysis, 13, 391-397.

Nicolis, G. and Prigogine, I., 1977, Self-Organization in Nonequilibrium Systems, Wiley, New York, $491 \mathrm{p}$.

Openshow, S., 1995, Commentary: human systems modeling as a new grand challenge area in science, Environment and Planning $A, 27,159-164$.

Phipps, M., 1989, Dynamic behavior of cellular automata under the constraint of neighborhood coherence, Geographical Analysis, 21, 197-215.

Phipps, M., 1992, From local to global. The lesson of cellular automata, In: DeAngelis, D.L. and Gross, L.J. (eds.), Individual-Based Models and Approaches in Ecology: Populations, Communities and Ecosystems, Chapman \& Hall, New York, pp. 165-187.

Phipps, M. and Langlois, A., 1997, Spatial dynamics, cellular automata and parallel processing computers, Environment and Planning B, 24, 193-204.

Portugali, J. and Benenson, I., 1994, Competing order parameters in a self-organizing city, In: Braun, G.O. (ed.), Managing and Marketing of Urban Development and Urban Life, Dietrich Reimer, Berlin, pp. 669-681.

Portugali, J., Benenson, I. and Omer, I., 1994, Socio-spatial residential dynamics: stability and instability within a selforganizing city, Geographical Analysis, 26, 321-340.

Portugali, J. and Benenson, I., 1995, Artificial planning experience by means of a heuristic sell-space model: simulating international migration in the urban process, Environment and Planning A, 27, 1647-1665.

Portugali, J. and Benenson, I., 1997, Human agents between local and global forces in a self-organizing city. 
In: Schweitzer, F. (ed.), Self-organization of Complex Structures: from Individual to Collective Dynamics, Gordon and Breach, London, pp. 537--546.

Portugali, J., Benenson, I. and Omer, I., 1997, Spatial cognitive dissonance and sociospatial emergence in a self-organizing city, Environment and Planning B, 24, 263-285.

Prigogine, I., 1967, Introduction to Thermodynamics of Irreversible Processes, 3rd edition, Interscience, NY, $147 \mathrm{p}$.

Putman, S., 1990, Equilibrium solutions and dynamics of integrated urban models. In: Anselin, L. and Madden, M. (eds.), New Directions in Regional Analysis. Integrated and Multi-regional Approach, Belhaven Press, London, pp. 48-65.

Rapini, L. and Rabino, G.A., 1997, An evolutionary urban cellular automata: The model and some first simulations. In: Conte, R., Hegselmann, R. and Terna, P. (eds.), Lecture Notes in Economics and Mathematical Systems, 456, Springer, Berlin, pp. 327-333.

Sanders, L., Pumain, D., Mathian, H., Guerin-Pace, F. and Bura, S., 1997, SIMPOP: a multiagent system for the study of urbanism, Environment and Planning B, 24, 287-306.

Schweitzer, F. and Steinbrink, J., 1997, Urban cluster growth: Analysis and computer simulations of urban aggregations, In: Schweitzer, F. (ed), Self-Organization of Complex Structures, from Individual to Collective Dynamics, Gordon and Breach, Amsterdam, pp. 501-518.

Tadei, R. and Williams, H.C.W.L., 1994, Performance indicators for evaluation with a dynamic urban model, In: Bertuglia, C.S.,
Leonardi, G., Occelli, S., Rabino, G.A., Tadei, R. and Wilson, A.G. (eds.), Urban Systems: Contemporary Approach to Modeling. Croom Helm, London, pp. 82-104.

Tobler, W., 1979, Cellular Geography, In: Gale, S. and Olison, G. (eds.), Philosophy in Geography, Kluwer, Dordrecht, pp. 379-386.

Troitzsch, K.G., Mueller, U., Gilbert, G.N. and Doran, J.E., (eds.), 1996, Social Science Microsimulations, Springer, Berlin, $471 \mathrm{p}$

White, R. and Engelen, G., 1993, Cellular automata and fractal urban form: a cellular modeling approach to the evolution of urban land use patterns, Environment and Planning A, 25, $1175-1199$.

White, R., Engelen, G. and Uljee, I., 1997, The use of constrained cellular automata for high-resolution modeling of urban landuse patterns, Environment and Planning B, 24, 323-343.

Van Wissen, L. and Rima, A., 1988, Modeling Urban Housing Market Dynamics. Evolutionary Pattern of Households and Housing in Amsterdam, Elsevier Science Publishers, $286 \mathrm{p}$.

$\mathrm{Wu}, \mathrm{F} ., 1996$, A linguistic cellular automata simulation approach for sustainable land development in a fast growing region, Computers, Environment and Urban Systems, 20, 367-387.

Zhang, W.B., 1989, Coexistence and separation of the two residential groups - an interactional spatial dynamic approach, Geographical Analysis, 21, 91-102. 


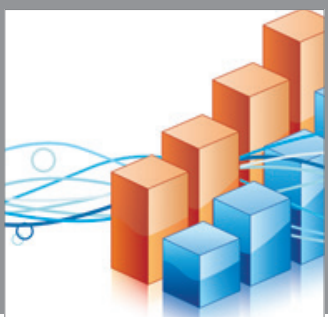

Advances in

Operations Research

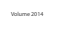

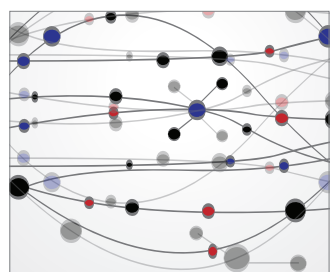

\section{The Scientific} World Journal
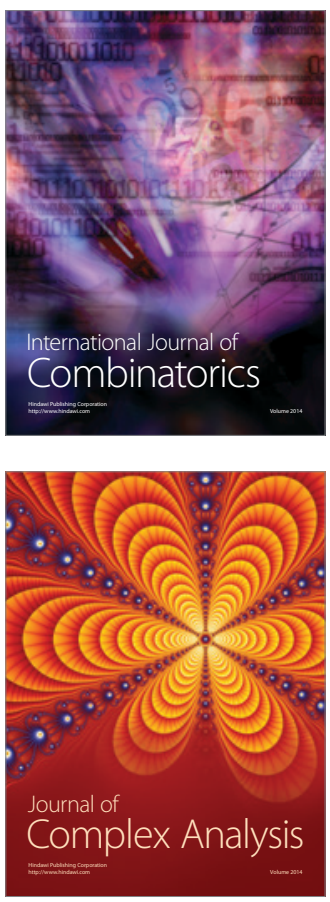

International Journal of

Mathematics and

Mathematical

Sciences
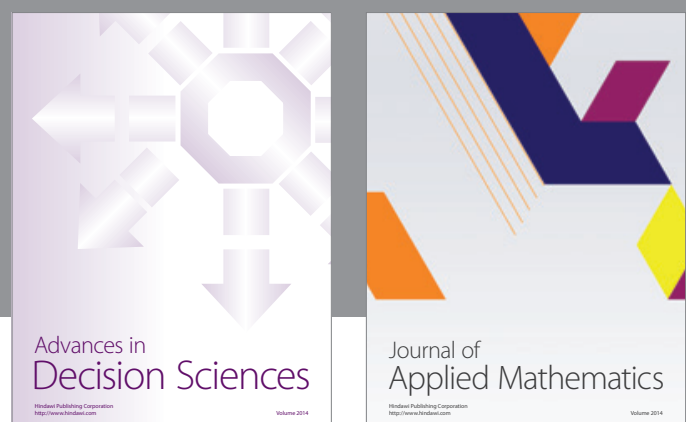

Journal of

Applied Mathematics
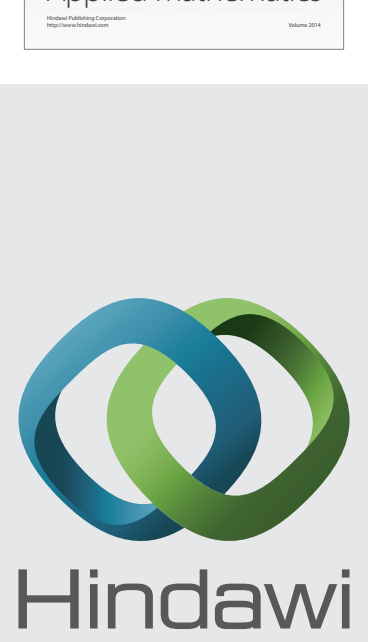

Submit your manuscripts at http://www.hindawi.com
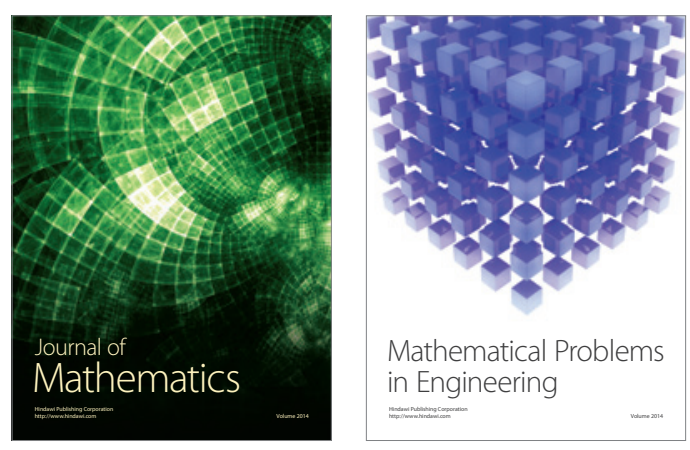

Mathematical Problems in Engineering
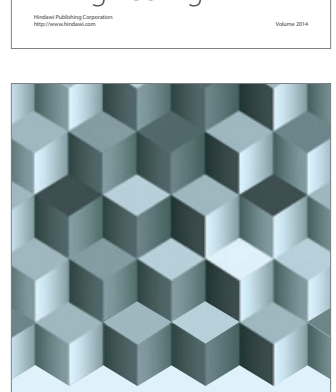

Journal of

Function Spaces
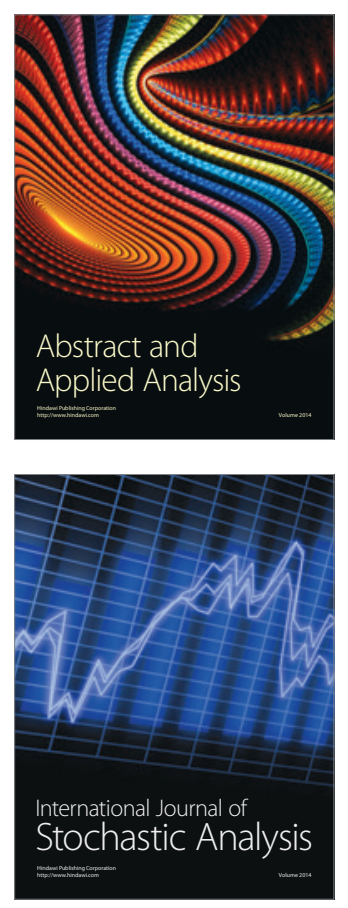

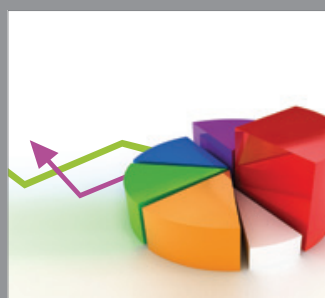

ournal of

Probability and Statistics

Promensencen
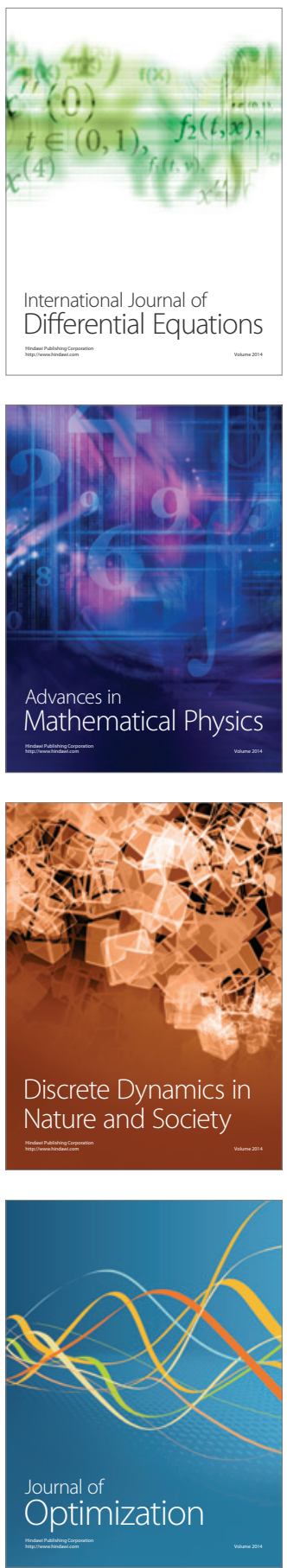